\title{
El Programa Más Médicos: un análisis complementario desde la perspectiva de la salud internacional
}

\author{
0 Programa Mais Médicos: uma análise complementar sobre a perspectiva da saúde internacional
}

\author{
The More Doctors Program: a further analysis from the perspective of international health
}

Mario Roberto Rovere ${ }^{(a)}$

El artículo constituye un importante aporte para comprender y para poner en valor un programa de gran escala, tomando "el toro por las astas" tal como el Sistema Brasileño de Salud (SUS) y el movimiento sanitario brasilero nos tiene acostumbrados desde hace mas de treinta años.

La "triangulación" propuesta en el artículo entre Brasil, Australia y EE UU ayuda a comprender las dificultades de garantizar la cobertura territorial de la medicina y la necesidad relativamente universal de generar mecanismos contrarios a la "tendencia espontanea" del empleo médico en países capitalistas.

Mis comentarios además de valorar este trabajo de objetivación y de triangulación sobre políticas activas de Recursos Humanos intenta ofrecer un análisis complementario también desde la perspectiva de la salud internacional.

La migración profesional y/o el drenaje de cerebros es un fenómeno mundial de larga data pero que se aceleró desde los años de 1990 bajo el impulso de la denominada "globalización" que - a diferencia de las migraciones del siglo XIX que requerían mano de obra masculina para las manufacturas- se caracterizó por "importar" mano de obra con predominio femenino para el área de servicios.

Las evidencias indican que las decisiones profesionales de los médicos resultan de una lógica que podríamos definir como "market oriented" lo que explica que el flujo internacional migratorio ocurra fundamentalmente "de sur a norte" de los países periféricos a los centrales, pero también al interior de nuestros países desde las zonas rurales o las pequeñas ciudades hacia las capitales y las grandes ciudades.

Un fenómeno que se verifica en los porcentajes de médicos extranjeros en EUA y en Australia y que resulta en proporciones aun mayores en varios países europeos como Gran Bretaña o España. Se afirma incluso que el estado de bienestar europeo solo se puede sostener por el peso relativo de los extranjeros en su fuerza laboral.

Usamos intencionadamente el término "market oriented" porque su contrapartida son las decisiones "policy oriented", es decir aquellas vinculadas con las convicciones, con la ideología, con las políticas públicas. Resulta imprescindible en ese sentido constatar que los únicos médicos que en gran escala migran de

"Norte a Sur" son los médicos cubanos. Un fenómeno que hasta incluso los EE UU

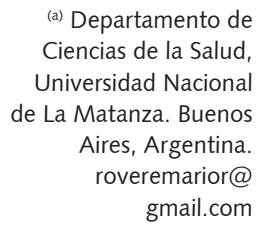

(a) Departamento de Ciencias de la Salud, Universidad Nacional de La Matanza. Buenos Aires, Argentina. roveremarior@ gmail.com 
han reconocido como consecuencia de la ayuda internacional cubana a los países africanos afectados por el Ébola.

Resulta en consecuencia fundamental incluir en este análisis la pregunta sobre porque nuestros países latinoamericanos con innumerables e importantes escuelas de medicina en prestigiosas universidades públicas, - es decir financiadas por todos los ciudadanos de un país, incluso por aquellos que nunca podrán asistir a ellas-, formamos fundamentalmente médicos "market oriented".

No se trata tan solo de una tendencia espontanea o de fallas en el mercado de trabajo. La estrategia principal de las profesiones liberales ha sido y es la de mantenerse en una fuerte sobre demanda, lo que requiere un férreo control de la "producción de profesionales" lo que en muchos países se verifica al ver que universidades públicas masivas tienen sistemas restrictivos "especiales" en sus carreras de medicina. Colocarse en sub-oferta no se explica solo por la búsqueda de ventajas económicas sino también para desplegar estrategias políticas orientadas a limitar las posibilidades de sistemas públicos extensos, como el propio SUS.

Este fenómeno se ha complejizado porque en algunos países como la Argentina se ha liberalizado la "producción de médicos" pero los mecanismos restrictivos se han desplazado al control de las especialidades, cuyas "sociedades científicas" han devenido en corporaciones dedicadas predominantemente a la regulación del ingreso a la especialidad.

La principal diferencia en perspectiva internacional del "Mais Médicos" comparado con Australia, EE UU y otros países centrales es ética ya que, no solo ha pactado con los países "proveedores" de profesionales - lo que en el caso de Argentina me consta personalmente - sino que, además ha definido un conjunto de países que por mostrar proporciones de médicos por habitante iguales o inferiores al Brasil no son elegibles para el programa.

De los otros "casos" internacionales también se pueden aprovechar elementos que pueden complementar las políticas públicas sobre empleo médico. La experiencia de Australia y de otros países involucrando a las universidades en sistemas de ingresos preferenciales y subsedes geográficamente desconcentradas, lo que en términos internacionales se conoce como "pipeline", permitiría que el mapa de alcance real de las universidades públicas no mostrara el contraste que muestra el mapa de la Figura 2 para Brasil pero que se repetiría en la mayoría de los países latinoamericanos.

Del caso norteamericano queda la inquietud sobre el sistema de crédito educativo y la compra de deuda por los programas de radicación en zonas más desprovistas de profesionales. Aun conociendo el rechazo generalizado en América latina a estas estrategias persiste la pregunta "¿Hasta qué punto las universidades y los sistemas de formación de posgrado de financiamiento público pueden continuar favoreciendo con sus sistemas de ingreso la formación de jóvenes de familias de alta renta con altas expectativas de migración, de sobre-especialización y de empleo en el sector privado?".

La experiencia venezolana resulta por demás elocuente. Cuenta con uno de los sistemas de educación médica en universidades públicas más extenso, sin embargo el gobierno debe apelar a una Escuela de Medicina paralela para contar con fuerza laboral para sus políticas públicas.

La experiencia argentina es menos conocida pero aun contando con universidades públicas gratuitas, los jóvenes de baja renta y de regiones geográficas apartadas acceden a la educación médica a través de la Escuela Latinoamericana de Educación Médica y luego resultan los principales o los únicos candidatos a radicarse y/o a ingresar en el sistema de residencias de medicina general en el interior del país.

En todos los casos no se trata de diferencias o de discusiones ideológicas, se trata de saber cómo y cuando fue que las universidades públicas dejamos de cumplir nuestros mandatos institucionales y sobre todo cual será el aporte que podremos hacer en el futuro para que un programa como el Mais Médicos no sea necesario, especialmente en una Región en donde se acepta que la salud es un derecho y que el Estado debe garantizar ese derecho. 